\title{
EDITORIAL
}

\section{RESEARCH IN NURSING HOMES IN THE TIME OF COVID}

\author{
Y. ROLLAND ${ }^{1,2}$, P. DE SOUTO BARRETO ${ }^{1,2}$ \\ 1. Gerontopole of Toulouse, Institute on Aging, Toulouse University Hospital (CHU Toulouse), Toulouse, France; 2. CERPOP Centre d'Epidémiologie et de Recherche en santé des \\ POPulations UPS/INSERM UMR 1295, Toulouse, France. Corresponding author: Professor Yves Rolland, Address: Gerontopole, 20 rue du Pont Saint-Pierre, Cité de la Santé, \\ CHU de Toulouse, 31059 Toulouse - France, Phone: (+33) 5617770 21, email: rolland.y@chu-toulouse.fr
}

Key words: COVID-19, nursing home, research.

The pandemic has generated an unprecedented research effort in human history. The drama experienced in longterm care facilities (LTCFs) during the epidemic period must however raise questions about the ability of the scientific community to find specific solutions for the oldest and most vulnerable people living in LTCFs in a timely manner.

Many epidemiological works carried out in developed countries such as France, the United States, Spain, Italy, Canada alarmed the medical community on a major number of deaths due to SARS-CoV-2 in LTCFs (1). Schematically, about $30 \%$ of all deaths due to SARS-CoV-2 concern residents of LTCFs $(2,3)$. This high percentage of deaths within a very minority subgroup of the population (1\% of the French population) contrasts with the low number of scientific studies involving residents of LTCFs. A quick search on the PudMed. gov website proves it. By filtering on the research carried out on "humans", only 694 references emerge by associating the keywords "nursing home" and "COVID-19" (less with "longterm care facility"). This number is derisory (around $0.49 \%$ ) compared to the 141,237 results obtained with the keyword "COVID-19" alone. To put it another way, 1 in approximately 200 COVID-related manuscripts to date relate to residents of LTCFs. Of course, this observation can be balanced by the research which, without focusing specially on the population living in LTCFs, has led to advances in the care of people living in LTCFs. Research on vaccination is one example among others. However, should we not again be surprised that before the massive and priority vaccination of the residents of LTCFs, none were included in the original work that led to the implementation of the vaccination against SARS-Cov-19 in all institution worldwide? To date, only 5 Randomized Controlled Trial (RCT) have been published on COVID-19 in "nursing home".

In the initial phase, the preventive measures implemented in the LTCFs relied on common sense and were mainly empirical (4). Yet, the severity of the epidemic in the LTCFs due to (i) the specificities of the population but also (ii) the organizational characteristics of the institutions justify a strong commitment for research work to bring improved geriatric medicine and quality of care in LTC during the pandemic. The very high age of the residents, their multiple morbidities, their undernutrition explain their immunosuppression and the high rate of deaths. The very high prevalence of neuro-degenerative diseases in LTCFs, often at severe stage and complicated with psychobehavioral disorders such as wandering compromise the feasibility in applying protective measures and in particular in wearing the mask. Finally, community life, in closed spaces, sometimes old and poorly ventilated, is conducive to the spread of the virus. The conjunction of these three factors (patients at very high risk of severe COVID-19/impossibility of applying health rules/promiscuity of many individuals in a closed place), made it possible, from the start of the pandemic in spring 2020, to announce a disaster in LTCFs. To this observation must be added the insufficient number of health care professional, their low level of training and equipment and sometimes the insufficient support provided by hospital staff overwhelmed by the workload in the emergency room.

Despite the need for research data in LTCF, many challenges must be overcome to conduct high-quality research in LTCF. More than ever, evidence-based medicine should guide the practices of caregivers in LTCFs and improve the care of residents. However, the pandemic has added challenges to an already difficult research to conduct in LTCF. In a systematic review, Lam et al. (5) report the multiples challenges, constraints and specificities of research in LTCFs. Among the challenges to be met, it is worth mentioning the increased costs of research in LTCFs compared to the community and few funding opportunities for research projects, the high turnover of health care professionals and residents, the heterogeneity of residents, the difficulty of recruitment to participate in research and in particular the obstacles to obtaining consent and assent of residents (in cognitively impaired residents with or without legal guard, among other ethical challenges), barriers related to relatives who are afraid of research and who do not want their relatives to be involved in clinical research, poor or complicated access to imaging or lab exams, low number and overloaded health care professional. Moreover, the directors and administrative officers of the LTCFs do not know the world of research and show little interest. Research in LTCF also generates concern that the data collected from residents and health care professional may lead to criticism or even controls of regulatory guardianship (6). In randomized placebo- 
controlled studies, the risk of contamination of participants is high if the intervention is not blinded as often in nonpharmacological interventions. It is difficult for the residents of the placebo group but also for the families and caregivers not to allow all the residents to benefit from the action taking place in the LTCF. The only option is then to organize a cluster randomization which however asks for the recruitment of a considerable number of LTCFs, with a higher risk of study abandonment by LTCFs in the control group.

In the context of the pandemic, with ban on visits and low human resources, these multiple challenges have often become insurmountable for the healthcare teams of LTCFs already overwhelmed by the management of a crisis situation, staffing shortages, and emotional burden.

The research conducted in the city or at the hospital cannot answer research questions specific to the population of LTCFs. What solutions can we anticipate to promote research in LTCFs for future comparable situations?

Encouraging research in LTCFs must be prioritized in funding research calls so that more researchers are interested in these patients and that networks capable of mobilizing their strength are created. The recommendation that "An investment is made in research priorities that address major public health problems and inequalities that affect older people receiving long-term care" listed by the International Association of Gerontology and Geriatrics (IAGG) nursing home initiative (7) is still lacking.

Research initiatives, leaded by public (academic) but also non- or for-profit institutions (private) should be promoted. Upstream work must be implemented to improve the responsiveness that we have been lacking during the pandemic. Awareness of research carried out in LTCFs should be more systematically carried out through international and national geriatrics congresses. The Nursing Home Research International Conference aims to contribute to fill this gap.

The creation of large national prospective and socioeconomic epidemiological databases such as the French health care database SNDS, the German sickness fund, the Nordics databases, or the CPDR \& HES in the United Kingdom opens up prospects for large-scale analysis of the health data (usual care, transition medicine, therapies, end of life) of LTCF residents if place of living in LTCF is indeed a data collected. Partnerships between academic researchers and groups of LTCFs (public or private) should be encouraged. Similarly, incentives should be found to value LTCFs engaging in the research effort. To date, the support provided to LTCFs fulfilling this research duty is usually not commensurate with the effort deployed.

Finally, the experience of validating COVID vaccines is typical of the treatment validation limits given for LTCF's residents. The vaccination campaign, which started in LTCFs, generated, at the initial phase, many concerns because no residents of LTCFs had been included in the princeps trials (8). However, how many anti-hypertensives, anti-diabetics, have been tested previously in a population of LTCFs? The evidence is that the subjects with the most access to these drugs, with the greatest risk of poor tolerance and drug interactions, are those who are the least investigated in therapeutic trials. Drug agencies should ensure that trials include residents of LTCFs before approval (7). Who would accept that new drugs tested in adults are automatically validated in pediatrics without prior trials in children? For this, simplified inclusion procedures (informed consent) should be considered.

In many areas, the pandemic has revealed the shortcomings of the systems in place. Health care professional in LTCFs have demonstrated a high quality of innovation and resilience $(9,10)$ but research carried out in LTCFs has not been up to the problem. Hopefully this drama will allow us to build more effective strategies of research in LTCFs for the future.

Funding sources: none.

Conflicts of interest: The Authors have nothing to disclose.

\section{References}

1. Thompson DC, Barbu MG, Beiu C, Popa LG, Mihai MM, Berteanu M, Popescu MN The Impact of COVID-19 Pandemic on Long-Term Care Facilities Worldwide: An Overview on International Issues. Biomed Res Int. 2020 Nov 4;2020:8870249. doi: $10.1155 / 2020 / 8870249$.

2. European Team Eurosurveillanc. Updated rapid risk assessment from ECDC on the novel coronavirus disease 2019 (COVID-19) pandemic: increased transmission in the EU/EEA and the UK. Euro Surveill. 2020 Mar 26; 25(12): 2003121. doi: 10.2807/1560-7917.ES.2020.25.12.2003261

3. Hsu AT, Lane N, Sinha SK, et al. Understanding the impact of COVID-19 on residents of Canada's long-term care homes - ongoing challenges and policy responses. :19. LTCcovid-country-reports_Canada_June-4-2020.pdf

4. Blain H, Rolland Y, Tuaillon E, Giacosa N, Albrand M, Jaussent A, Benetos A, Miot S, Bousquet J. Efficacy of a Test-Retest Strategy in Residents and Health Care Personnel of a Nursing Home Facing a COVID-19 Outbreak. J Am Med Dir Assoc. 2020 Jul;21(7):933-936. doi: 10.1016/j.jamda.2020.06.013.

5. Lam HR, Chow S, Taylor K, Chow R, Lam H, Bonin K, Rowbottom L, Herrmann N. Challenges of conducting research in long-term care facilities: a systematic review. BMC Geriatr. 2018 Oct 12;18(1):242. doi: 10.1186/s12877-018-0934-9.

6. Zapka J, Amella E, Magwood G, Madisetti M, Garrow D, Batchelor-Aselage M. Challenges in efficacy research: the case of feeding alternatives in patients with dementia. J Adv Nurs. 2014;70(9):2072-85. doi: 10.1111/jan.12365.

7. Rolland Y, Tolson D, Morley JE, Vellas B. The International Association of Gerontology and Geriatrics (IAGG) nursing home initiative. J Am Med Dir Assoc. 2014 May;15(5):307-8. doi: 10.1016/j.jamda.2014.03.002.

8. Polack FP, Thomas SJ, Kitchin N, Absalon J, Gurtman A, Lockhart S, Perez JL, Pérez Marc G, Moreira ED, Zerbini C, Bailey R, Swanson KA, Roychoudhury S, Koury K, Li P, Kalina WV, Cooper D, Frenck RW Jr, Hammitt LL, Türeci Ö, Nell H, Schaefer A, Ünal S, Tresnan DB, Mather S, Dormitzer PR, Sahin U, Jansen KU, Gruber WC; C4591001 Clinical Trial Group. Safety and Efficacy of the BNT162b2 mRNA Covid-19 Vaccine. N Engl J Med. 2020 Dec 31;383(27):2603-2615. doi: 10.1056/NEJMoa2110345.

9. Lingum NR, Sokoloff LG, Meyer RM, Gingrich S, Sodums DJ, Santiago AT, Feldman S, Guy S, Moser A, Shaikh S, Grief CJ, Conn DK. Building Long-Term Care Staff Capacity During COVID-19 Through Just-in-Time Learning: Evaluation of a Modified ECHO Model. J Am Med Dir Assoc. 2021 Feb;22(2):238-244.e1. doi: 10.1016/j.jamda.2020.10.039.

10. Rolland Y, Benetos A, Villars H, Braun H, Blain H. Editorial: A COVID-19 Support Platform for Long Term Care Facilities. J Nutr Health Aging. 2020;24(5):461-462. doi: 10.1007/s12603-020-1364-x. 